\title{
Dietary Lactic Acid Bacteria Modulate Yolk Components and Cholesterol Metabolism by Hmgr Pathway in Laying Hens
}

Original Article

\section{-Author(s)}

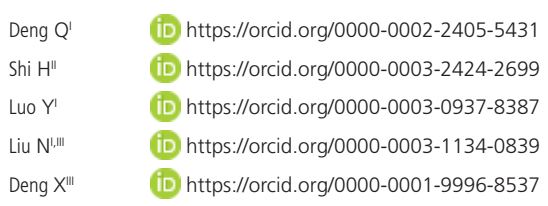

Department of Animal Science, Henan University of Science and Technology, Luoyang, China. Department of Poultry Science, University of Georgia, Athens, GA, USA

National Engineering Research Center of Biological Feed, Beijing, China.

\section{Mail Address}

Corresponding author e-mail address Ning Liu

Room 525, Dongke Building, Kaiyuan Avenue No. 263, Luoyang 471023, China.

Phone: +86 37964282341

Email: ningliu68@163.com

\section{ABSTRACT}

This study aimed to investigate the effect of dietary lactic acid bacteria (LAB) on egg production, yolk components, cholesterol metabolism, and enterohepatic circulation of bile acids in hens. Four treatment diets included a control and LAB added at $3 \times 10^{5}$ (low), $3 \times 10^{7}$ (medium), or $3 \times 10^{9}$ (high) cfu/kg. The treatment LAB contained equal amounts of Lactobacillus acidophilus, Lactobacillus plantarum, and Enterococcus faecium. Results showed that high $L A B$ increased $(p<0.05)$ laying rate, egg mass, and yolk phospholipid, but decreased $(p<0.05)$ yolk triglyceride and phosvitin. Diets with LAB decreased $(p<0.05)$ yolk and serum cholesterol content, and serum bile acid by 9.3 to $39.9 \%$. In liver, high LAB downregulated $(p<0.05)$ mRNA expression of serine/threonine kinase 11 (STK11), 3-hydroxy-3-methylglutaryl-CoA reductase (HMGR), AMP-activated protein kinase catalytic subunit (PRKAA1, 2), and protein phosphatase catalytic subunits (PPP2CA, PPP2CB and PPP3CA) by 49.5 to $175.4 \%$. In mucosa, high LAB downregulated $(p<0.05)$ PRKAA1 and HMGR by 68.2 and $69.6 \%$, respectively; but upregulated $(p<0.05)$ PPP2CA and PPP2CB by 51.2 and $45 \%$, respectively. Linear decreasing $(p \leq 0.035)$ responses to $L A B$ doses were found on cholesterol, phosvitin, bile acid, and hepatic gene expressions, and quadratic $(p \leq 0.006)$ effects on yolk cholesterol and hepatic STK11. It is concluded that probiotic LAB can improve yolk components and decrease hepatic cholesterol synthesis by regulating HMGR pathway in hens.

\section{INTRODUCTION}

Lactic acid bacteria (LAB) such as Lactobacillus acidophilus (L. acidophilus), Lactobacillus plantarum (L. plantarum), and Enterococcus faecium (E. faecium) are among the most important groups of microorganisms used in food fermentations and health promotion. Clinical trials showed that LAB ingested in sufficient numbers produced nutrition and health benefits with regards to nutrient digestibility, gut microbiota, immunity, and metabolism (Saez-Lara et al., 2015; Wang et al., 2018; Wang et al., 2019a,b; Zhao et al., 2020). Cholesterol is an essential structural component of lipid membranes and a precursor to steroid hormones and bile acids; biosynthesized by all animal cells, but primarily by hepatocytes (Howles, 2016). Eggs and meat are the main dietary sources for cholesterol (Ahn et al., 1999). Excess dietary cholesterol coupled with its hepatic biosynthesis can lead to hypercholesterolemia and so threaten cardiovascular health (Cha and Park, 2019). It is therefore considered desirable to reduce the cholesterol content in animal derived foods.

Recent dietary intervention with $L A B$ found that it contributed to improving lipid metabolism and reducing cholesterol. L. plantarum reduced serum triglyceride, cholesterol, low-density lipoprotein 
and very-low-density lipoprotein cholesterol, and atherogenic index in rats (Aminlari et al., 2018). The combination of $L$. acidophilus and $\beta$-cyclodextrin lowered $27.9 \%$ serum low-density lipoprotein cholesterol in pigs (Alonso et al., 2016). Pediococcus acidilactici supplements fed to hens reduced yolk cholesterol by more than 10\% (Mikulski et al., 2012). One of the potential mechanism for cholesterol reduction by probiotics is the deconjugation or excretion of bile salts. L. plantarum induced bile acid synthesis, enhanced bile flow and biliary glutathione output, and fecal bile acid excretion in mice (Zhai et al., 2019). L. acidophilus affected intestinal bile acid composition and vitamin $\mathrm{E}$ acetate metabolism of mice (Roager et al., 2014), but L. plantarum had no effect on stool bile acids, serum lipids, glucose, and insulin in healthy obese adults (Culpepper et al., 2019). Notably, besides into bile acid, cholesterol is also metabolized into steroids and vitamin D, whether probiotics influence their enterohepatic circulation or circulating concentrations is unknown.

The reaction catalyzed by 3-hydroxy-3methylglutaryl-COA reductase (HMGR) is the rate limiting step in de novo cholesterol biosynthesis (Howles, 2016). This enzyme is further modified by AMP-activated protein kinase (AMPK) and protein phosphatases of the 2A family (PP2A), and serine/ threonine kinase 11 (STK11). Because probiotics are capable of improving lipid metabolism and reducing cholesterol, we hypothesized that they may act in part through changes in HMGR activity and its downstream products in farm animals. The present study aimed to investigate the effect of $L A B$ on the egg production, yolk components, cholesterol and its metabolites, and gene expression related to cholesterol synthesis in laying hens.

\section{MATERIALS AND METHODS}

\section{LAB strains and diets}

Lactic acid bacteria strains including L. acidophilus (ACCC11073), L. plantarum (CICC21863), and E. faecium (CICC20430) were obtained from the Animal Biotechnology Lab in Henan University of Science and Technology (Luoyang, China). The strains were combined at an equal amount and added into a basal diet at final dose rates of 0 (control), $3.0 \times 10^{5}$ (low), 3.0 $\times 10^{7}$ (medium), or $3.0 \times 10^{9}$ (high) colony forming unit (cfu) $/ \mathrm{kg}$ of diet. A total of $1.00 \mathrm{~g}$ of the strain powder was diluted with $9 \mathrm{~mL}$ of $1 \%$ Tryptic Soy Broth medium (TSB, Hopebio-Technology Co., Ltd, Qingdao, China) and then homogenized. Viable counts of bacteria were conducted by plating serial 10-fold dilutions onto TSB agar plates after cultured at anaerobically $37^{\circ} \mathrm{C}, \mathrm{pH}$ 6.2 , for $24 \mathrm{~h}$. Compositions and nutrient levels of the basal diet are listed in Table 1.

Table 1 - Composition and nutrient level of basal diet (air-dry basis).

\begin{tabular}{|c|c|c|c|}
\hline Ingredient & Content, g/kg & Nutrient ${ }^{* *}$ & Content, g/kg \\
\hline Corn & 604 & Metabolizable energy, MJ/kg & 11.28 \\
\hline Soybean meal & 235 & Crude protein & 175.3 \\
\hline Corn gluten & 45 & $\mathrm{Ca}$ & 35.1 \\
\hline Met & 2 & Non-phytate P & 4.5 \\
\hline Salt & 4 & Met & 5.0 \\
\hline Di-calcium phosphate & 15 & Lys & 8.2 \\
\hline Limestone & 85 & Met+Cys & 7.9 \\
\hline Premix * & 10 & & \\
\hline
\end{tabular}

*Provides (per kg of diet): vitamin A (retinyl acetate), 8,000 IU; cholecalciferol, 1,600 IU; vitamin E (DL- $\alpha$-tocopheryl acetate), 5 IU; vitamin K, 0.5 mg; riboflavin, 2.5 mg; D-pantothenic acid, 2.2 mg; niacin, 20 mg; pyridoxine, 3.0 mg; biotin, 0.10 mg; folic acid, 0.25 mg; vitamin B12, 0.004 mg; choline, 500 mg; manganese, 60 mg; iodine, 0.35 mg; iron, 60 mg; copper, $8 \mathrm{mg}$; zinc, $80 \mathrm{mg}$; and selenium, $0.30 \mathrm{mg}$.

${ }^{* *}$ Calculated by Chinese Feed Database $(2014,25$ th ed).

\section{Animals and samples}

The Institutional Committee for Animal Use and Ethics of Henan University of Science and Technology approved the experimental protocol of this study.

One hundred and ninety two, 23 wk old Hyline brown laying with similar body weights (mean \pm SEM, $1796 \mathrm{~g} \pm 4.10$ ) were allocated randomly into 4 treatment groups, with 6 replicates per treatment and 8 laying hens per replicate. All hens were housed in 3-tiered cages at the Gonghua Poultry Company (Luoyang, China) with free access to feed and water at all times. During the period, hens received $16 \mathrm{~h} \mathrm{light/d}$ within ventilated houses (airflow rate here). Hens were observed during a 1-wk adjustment period to monitor health status and egg production prior to the start of the 6 wk experiment. Feed intake, laying rate, and egg weight were recorded daily for each replicate.

All eggs laid during the last $3 \mathrm{~d}$ of the trial were collected from each replicate. A subsample of 15 eggs 
from each replicate were selected randomly for analysis. At the end of the feeding trial, 6 hens were randomly selected from each replicate and venous blood collected from the right wing for serum preparation (Liu et al., $2018 \mathrm{a}, \mathrm{b}$ ). The birds were euthanized by $\mathrm{CO}_{2}$ inhalation prior to harvest of the entire liver. Intestinal mucosa was collected from a $10 \mathrm{~cm}$ (approximate) section of proximal jejunum following removal of digesta by deionized water $\left(0\right.$ to $\left.4^{\circ} \mathrm{C}\right)$ flushes. The liver and mucosa samples were halved. One portion of each tissue type was stored in RNA later for gene expression analysis, while the other portion was stored at $-80^{\circ} \mathrm{C}$ for chemical quantification.

\section{Biochemical analysis}

Phospholipid (Catalog No. MET-5085), total cholesterol (Catalog No. STA-390), and triglyceride (STA-397) contents of yolk and serum were measured using commercial kits (Cell Biolabs, Inc., San Diego, (A, USA) and Fluoroskan ${ }^{\mathrm{TM}}$ Microplate Fluorometer (Thermo Scientific, Waltham, MA, USA). Yolk phosvitin was quantified by ELISA kit (Abbkine Scientific Co., Ltd., Wuhan, China). IgY Chicken SimpleStep ELISATM Kit, Total Bile Acid Assay Kit (Fluorometric, MET-5005) from Abcam Trading Co. Ltd. (Shanghai, China), Pregnenolone ELISA Kit (Catalog No. E4633) from
Biovision Incorporated (Milpitas, CA, USA), and Calcitriol ELISA Kit (Catalog No. KC0962) from Aviva Systems Biology, Corp. (San Diego, CA, USA) were also used for biochemical parameter analysis. The sample preparation and analytical procedures were carried out according to manuals and literature (Liu et al., 2010; Ding et al., 2019 $a, b)$. All samples were assayed in triplicate. Biochemical components in jejunal mucosa were expressed as concentration relative to per gram mucosal protein.

Reagents, primer synthesis and CDNA sequencing for RT-qPCR analysis were provided by TaKaRa Co. Ltd. (Dalian, China). Gene expression data was analyzed by the comparative $C_{T}$ method using beta-actin gene as an internal control in the treated and untreated samples according to the method by Schmittgen and Livak (2008). The qPCR reactions were set at $10 \mu \mathrm{L}$ with $5 \mu \mathrm{L}$ of SYBR Green Master Mix, $1 \mu \mathrm{L}$ of primer (Table 2), $4 \mu \mathrm{L}$ of $10 \times$ diluted cDNA. All qPCRs were run in triplicate using the same thermal cycles $\left(50^{\circ} \mathrm{C}\right.$ for $2 \mathrm{~min}, 95^{\circ} \mathrm{C}$ for $10 \mathrm{~min}, 40$ cycles of $95^{\circ} \mathrm{C}$ for 15 $\mathrm{s}$ and $60^{\circ} \mathrm{C}$ for $1 \mathrm{~min}$ ) on the $\mathrm{ABI}$ Prism $7900 \mathrm{HT}$ Fast Real-Time PCR System. No amplification signal was detected in water or no-RT RNA control samples.

\section{Statistical analysis}

Data are reported as grand means and standard error of the mean(SEM) for the six replicate means in

Table 2 - Information of primers for quantitative real-time PCR.

\begin{tabular}{|c|c|c|c|c|}
\hline \multirow[b]{2}{*}{ Name } & \multirow[b]{2}{*}{ GenBank } & \multicolumn{2}{|c|}{ Primers $\left(5^{\prime} \rightarrow 3^{\prime}\right)$} & \multirow{2}{*}{$\begin{array}{c}\text { Length } \\
\text { (bp) }\end{array}$} \\
\hline & & Forward & Reverse & \\
\hline STK11 & NM_001045833.1 & tggtgcccatacctcctagc & tggtgcccatacctcctagc & 244 \\
\hline PRKAA1 & NM_001039603.1 & caagtagtgtctcgcacggt & gactgatagctggtcccacg & 133 \\
\hline PRKAA2 & NM_001039605.1 & ttcggcaaagtcaaggttgg & gaagaagtctgttggcgtgc & 192 \\
\hline HMGR & NM_204485.2 & ttctcggccgggcgattt & tacagcgtgtgattgtcagga & 256 \\
\hline PPP2CA & nm_001006152.1 & tgttcaccaaggagctcgac & ctgtgacaggacatcgcact & 147 \\
\hline PPP2CB & NM_205124.1 & gctcaccaactcgtcatgga & gtacgacgggtaacgtgagg & 194 \\
\hline PPP3CA & XM_025149952.1 & cgtgtaaacacagcccgttt & ggccatggatgtctccacaa & 271 \\
\hline Beta-actin & NM_205518 & gccgagagagaaattgtgcg & cacaggactccatacccaaga & 208 \\
\hline
\end{tabular}

HMGR, 3-hydroxy-3-methylglutaryl-CoA reductase; PPP2CA, protein phosphatase 2 catalytic subunit alpha; PPP2CB, protein phosphatase 2 catalytic subunit beta; PPP3CA, protein phosphatase 3 catalytic subunit alpha; PRKAA1, AMP-activated protein kinase catalytic subunit alpha-1; PRKAA2, protein kinase AMP-activated catalytic subunit alpha-2; and STK11, serine/threonine kinase 11.

each treatment group. All calculations were carried out using SPSS software (IBM SPSS, version 23, Armonk, NY, USA). Differences between mean values of normally distributed data were assessed with one-way ANOVA and Tukey'b-test at $p<0.05$ level of significance, and Tamhane's 12 test for parameters with heterogeneity variance. The mean values from each replicate pen was the statistical unit for growth performance and parameters from the serum, liver, and jejunal mucosa, and the mean of the 15 eggs subsamples from each replicate pen was the statistical unit for yolk components. The response trend of experimental parameter to the three $L A B$ doses was analyzed using contrasts of linear and quadratic polynomial.

\section{RESULTS}

\section{Effect of dietary LAB on egg production and yolk components}

The addition of $L A B$ at $3 \times 10^{9} \mathrm{cfu} / \mathrm{kg}$ improved $(p<0.05)$ laying rate and egg mass, compared to the control diet, and linear responses $(p \leq 0.043)$ to $L A B$ doses 
were found for feed intake, laying rate, egg mass, and egg weight (Table 1). For yolk components, LAB at $3 \times$ $10^{9} \mathrm{cfu} / \mathrm{kg}$ decreased $(p<0.05)$ triglyceride and phosvitin, but increased $(p<0.05)$ phospholipid; the three doses of
LAB decreased $(p<0.05)$ cholesterol by 19.9 to $43.7 \%$. Linear responses $(p \leq 0.002)$ were found for phospholipid, cholesterol, and phosvitin, and quadratic responses $(p \leq 0.008)$ for phospholipid and cholesterol.

Table 3 - Effect of dietary lactic acid bacteria on egg production and yolk components of laying. hens.

\begin{tabular}{|c|c|c|c|c|c|c|c|}
\hline \multirow[b]{2}{*}{ Item } & \multirow[b]{2}{*}{ Control } & \multicolumn{3}{|c|}{ Lactic acid bacteria, cfu/kg } & \multirow[b]{2}{*}{ SEM } & \multicolumn{2}{|c|}{$p$ value } \\
\hline & & $3 \times 10^{5}$ & $3 \times 10^{7}$ & $3 \times 10^{9}$ & & Linear & Quadratic \\
\hline \multicolumn{8}{|l|}{ Egg production } \\
\hline Feed intake, g/day & 97.00 & 96.77 & 96.89 & 97.50 & 1.417 & 0.019 & 0.307 \\
\hline Laying rate, \% & $80.76^{b}$ & $81.00^{\mathrm{b}}$ & $82.59^{\mathrm{ab}}$ & $83.63^{a}$ & 0.512 & 0.013 & 0.532 \\
\hline Egg mass, g/day & $41.87^{b}$ & $41.84^{b}$ & $42.67^{a b}$ & $43.13^{\mathrm{a}}$ & 0.274 & 0.012 & 0.377 \\
\hline Egg weight, g/egg & 51.86 & 51.65 & 51.68 & 51.58 & 0.303 & 0.043 & 0.714 \\
\hline Feed/mass & 2.317 & 2.313 & 2.271 & 2.260 & 0.030 & 0.086 & 0.235 \\
\hline \multicolumn{8}{|c|}{ Yolk components, mg/g } \\
\hline Triglyceride & $206.9^{a}$ & $196.3^{\mathrm{ab}}$ & $194.9^{\mathrm{ab}}$ & $189.2^{b}$ & 3.668 & 0.134 & 0.579 \\
\hline Phospholipid & $91.69^{b}$ & $93.10^{\mathrm{b}}$ & $91.92^{b}$ & $97.61^{a}$ & 0.896 & 0.002 & 0.004 \\
\hline Cholesterol & $15.50^{\mathrm{a}}$ & $12.93^{b}$ & $12.35^{c}$ & $10.79^{d}$ & 0.115 & $<0.001$ & 0.008 \\
\hline Phosvitin & $27.63^{a}$ & $28.15^{a}$ & $26.41^{\mathrm{ab}}$ & $24.86^{b}$ & 0.526 & $<0.001$ & 0.878 \\
\hline $\lg Y$ & 3.73 & 3.95 & 4.13 & 4.13 & 0.155 & 0.436 & 0.628 \\
\hline
\end{tabular}

a-d Means within a row without a common superscript are significantly different, $p<0.05$.

Effect of dietary LAB on tissue cholesterol and its metabolites

Compared to the control, the three doses of dietary LAB also decreased $(p<0.05)$ cholesterol by 14.3 to $43.1 \%$ in the serum and jejunal mucosa, and serum bile acid by 17.4 to $41.5 \%$ (Table 4 ). In the jejunal mucosa, bile acid content was reduced $(p<0.05)$ with LAB at $3 \times 10^{5}$ and $3 \times 10^{9} \mathrm{cfu} / \mathrm{kg}$. Linear effects $(p \leq 0.034)$ were found on cholesterol, bile acid, and calcitriol in the serum, and cholesterol in the jejunal mucosa.

\section{Effect of dietary LAB on the expression of genes related to cholesterol synthesis}

In the liver, the three doses of dietary $L A B$ downregulated $(p<0.05)$ the mRNA expression of STK11, AMP-activated protein kinase catalytic subunit alpha-1 (PRKAA1), HMGR, protein phosphatase
2 catalytic subunit alpha (PPP2CA), and protein phosphatase 2 catalytic subunit beta (PPP2CB), compared to the control (Table 5). LAB doses at 3 $\times 10^{7}$ and $3 \times 10^{9} \mathrm{cfu} / \mathrm{kg}$ downregulated $(p<0.05)$ protein kinase AMP-activated catalytic subunit alpha 2 (PRKAA2) and protein phosphatase 3 catalytic subunit alpha (PPP3CA). Linear responses $(p \leq 0.035)$ were found for all the target genes, and quadratic responses $(p \leq 0.006)$ for STK11 and PPP2CB.

In the jejunal mucosa, compared to the control, LAB at $3 \times 10^{9} \mathrm{cfu} / \mathrm{kg}$ downregulated $(p<0.05)$ the gene expression of PRKAA 1 , but upregulated $(p<0.05)$ PPP2CA. LAB at any of the three doses downregulated $(p<0.05)$ HMGR by 30.7 to $93.2 \%$, but upregulated $(p<0.05)$ PPP2CB by 43.0 to $57.0 \%$. Expression of PRKAA1, PRKAA2, and HMGR decreased linearly in response to $L A B$ doses $(p \leq 0.035)$.

Table 4 - Effect of dietary lactic acid bacteria on tissue cholesterol and its metabolites in laying hens.

\begin{tabular}{|c|c|c|c|c|c|c|c|}
\hline \multirow[b]{2}{*}{ Item } & \multirow[b]{2}{*}{ Control } & \multicolumn{3}{|c|}{ Lactic acid bacteria, cfu/kg } & \multirow[b]{2}{*}{ SEM } & \multicolumn{2}{|c|}{$p$ value } \\
\hline & & $3 \times 10^{5}$ & $3 \times 10^{7}$ & $3 \times 10^{9}$ & & Linear & Quadratic \\
\hline \multicolumn{8}{|l|}{ Serum } \\
\hline Cholesterol, mg/dL & $169.9^{a}$ & $145.6^{b}$ & $129.5^{b}$ & $124.1^{b}$ & 5.780 & 0.009 & 0.392 \\
\hline Pregnenolone, ng/dL & 337.1 & 346.5 & 336.6 & 349.2 & 9.368 & 0.860 & 0.409 \\
\hline Bile acid, $\mu \mathrm{g} / \mathrm{dL}$ & $159.9^{a}$ & $132.1^{\mathrm{b}}$ & $110.2^{c}$ & $93.61^{d}$ & 3.264 & $<0.001$ & 0.540 \\
\hline Calcitriol, $\mu \mathrm{g} / \mathrm{dL}$ & $2.83^{\mathrm{ab}}$ & $2.65^{\mathrm{b}}$ & $2.82^{\mathrm{ab}}$ & $2.95^{\mathrm{a}}$ & 0.048 & 0.002 & 0.779 \\
\hline \multicolumn{8}{|c|}{ Jejunal mucosa, per g mucosal protein } \\
\hline Cholesterol, mg & $64.94^{\mathrm{a}}$ & $42.62^{b}$ & $37.55^{b}$ & $36.90^{\mathrm{b}}$ & 1.757 & 0.034 & 0.314 \\
\hline Pregnenolone, ng & 197.6 & 200.9 & 198.3 & 197.6 & 6.087 & 0.703 & 0.902 \\
\hline Bile acid, $\mu g$ & $76.85^{a}$ & $70.48^{b}$ & $72.99^{a b}$ & $68.91^{b}$ & 1.550 & 0.476 & 0.098 \\
\hline Calcitriol, $\mu \mathrm{g}$ & 1.06 & 1.04 & 1.02 & 0.94 & 0.062 & 0.385 & 0.728 \\
\hline
\end{tabular}

\footnotetext{
${ }^{\text {a-d }}$ Means within a row without a common superscript are significantly different, $p<0.05$.
} 
Table 5 - Effect of dietary lactic acid bacteria on the expression of genes related to cholesterol synthesis in laying hens.

\begin{tabular}{|c|c|c|c|c|c|c|c|}
\hline \multirow[b]{2}{*}{ Item } & \multirow[b]{2}{*}{ Control } & \multicolumn{3}{|c|}{ Lactic acid bacteria, cfu/kg } & \multirow[b]{2}{*}{ SEM } & \multicolumn{2}{|l|}{$p$ value } \\
\hline & & $3 \times 10^{5}$ & $3 \times 10^{7}$ & $3 \times 10^{9}$ & & Linear & Quadratic \\
\hline \multicolumn{8}{|c|}{ Liver (mRNA, $2^{-\Delta \Delta c t)}$} \\
\hline STK11 & $7.75^{a}$ & $6.02^{b}$ & $6.47^{b}$ & $4.70^{c}$ & 0.241 & 0.005 & 0.006 \\
\hline PRKAA1 & $5.28^{a}$ & $3.73^{b}$ & $3.53^{\mathrm{bc}}$ & $2.79^{c}$ & 0.148 & 0.001 & 0.212 \\
\hline PRKAA2 & $2.67^{a}$ & $2.76^{a}$ & $2.11^{b}$ & $1.72^{c}$ & 0.077 & $<0.001$ & 0.204 \\
\hline HMGR & $4.23^{a}$ & $2.86^{b}$ & $2.14^{c}$ & $1.53^{\mathrm{d}}$ & 0.135 & $<0.001$ & 0.764 \\
\hline PPP2CA & $4.88^{a}$ & $3.85^{b}$ & $4.04^{b}$ & $3.20^{c}$ & 0.118 & 0.003 & 0.004 \\
\hline PPP2CB & $2.32^{a}$ & $1.89^{b}$ & $1.66^{\mathrm{bc}}$ & $1.50^{c}$ & 0.079 & 0.005 & 0.771 \\
\hline PPP3CA & $3.25^{\mathrm{a}}$ & $2.80^{\mathrm{ab}}$ & $2.17^{\mathrm{bc}}$ & $2.30^{c}$ & 0.131 & 0.035 & 0.061 \\
\hline \multicolumn{8}{|c|}{ Jejunal mucosa (mRNA, $2^{-\Delta \Delta C t}$ ) } \\
\hline STK11 & 1.79 & 1.63 & 1.49 & 1.76 & 0.165 & 0.562 & 0.309 \\
\hline PRKAA1 & $3.15^{\mathrm{a}}$ & $2.79^{a b}$ & $2.40^{b c}$ & $1.87^{c}$ & 0.155 & 0.001 & 0.709 \\
\hline PRKAA2 & 3.40 & 3.35 & 3.10 & 2.86 & 0.143 & 0.035 & 0.968 \\
\hline HMGR & $5.25^{\mathrm{a}}$ & $4.01^{b}$ & $2.71^{c}$ & $3.09^{c}$ & 0.185 & 0.002 & 0.001 \\
\hline PPP2CA & $3.33^{b}$ & $4.29^{a b}$ & $3.75^{\mathrm{ab}}$ & $5.04^{a}$ & 0.345 & 0.155 & 0.052 \\
\hline PPP2CB & $3.63^{b}$ & $5.19^{a}$ & $5.70^{a}$ & $5.26^{a}$ & 0.231 & 0.811 & 0.076 \\
\hline РPР3СА & 3.50 & 3.48 & 3.19 & 3.73 & 0.334 & 0.607 & 0.341 \\
\hline
\end{tabular}

a-d Means within a row without a common superscript are significantly different, $p<0.05$.

HMGR, 3-hydroxy-3-methylglutaryl-CoA reductase; PPP2CA, protein phosphatase 2 catalytic subunit alpha; PPP2CB, protein phosphatase 2 catalytic subunit beta; PPP3CA, protein phosphatase 3 catalytic subunit alpha; PRKAA1, AMP-activated protein kinase catalytic subunit alpha-1; PRKAA2, protein kinase AMP-activated catalytic subunit alpha-2; STK11, serine/threonine kinase 11.

Figure 1 exhibits the relationship of HMGR pathway activity and mRNA expression influenced by dietary $L A B$ at $3 \times 10^{9} \mathrm{cfu} / \mathrm{kg}$ of feed compared to the control diet. In the liver, all target genes were downregulated marked as (-), indicating that the LAB may slow cholesterol biosynthesis. In the jejunal mucosa, similar results were found for PRKAA1 and HMGR, but STK11 and PRKAA1 were not affected as (o), and PP2A subunits PPP2CA and PPP2CB were upregulated as (+).

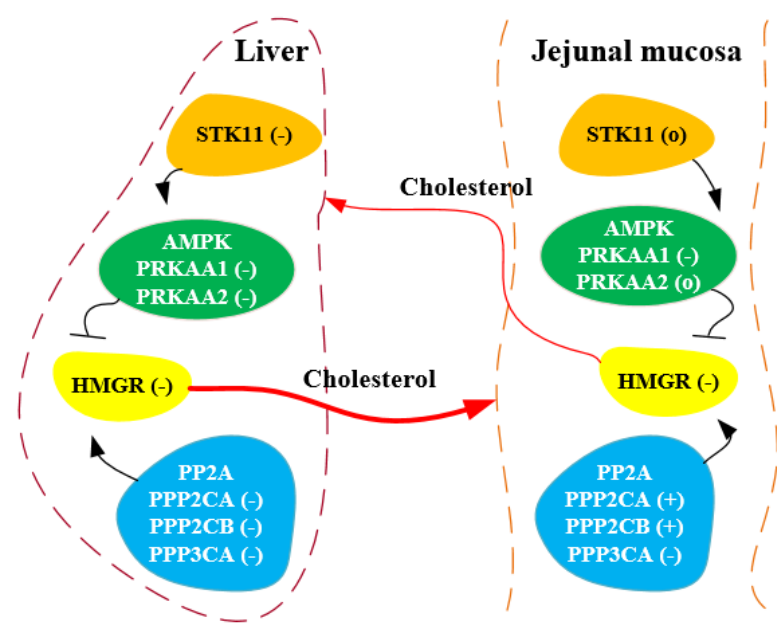

Figure 1 - Effect of lactic acid bacteria on HMGR pathway of cholesterol synthesis. $(-),(0)$, and $(+)$ denote that gene mRNA expression is downregulated, unaffected, and upregulated, respectively, compared to the control diet, for hens fed a diet containing lactic acid bacteria at $3 \times 109$ cfu/kg. AMPK, AMP-activated protein kinase; HMGR, 3-hydroxy-3-methylglutaryl-CoA reductase; PP2A, protein phosphatases of the 2A family; PPP2CA, protein phosphatase 2 catalytic subunit alpha; PPP2CB, protein phosphatase 2 catalytic subunit beta; PPP3CA, protein phosphatase 3 catalytic subunit alpha; PRKAA1, AMP-activated protein kinase catalytic subunit alpha-1; PRKAA2, protein kinase AMP-activated catalytic subunit alpha-2; STK11, serine/threonine kinase 11.

\section{DISCUSSION}

In the present study, dietary $L A B$ including $L$. acidophilus, L. plantarum, and E. faecium increased laying rate and egg mass, indicating the potential benefits of the probiotics in the host health and nutrition. This was supported by the studies that $L A B$ improved growth performance and nutrient digestibility of broiler chickens (Liu et al., 2018a,b). Furthermore, the per gram yolk concentrations of triglyceride, cholesterol, phospholipid, and phosvitin were also influenced by the dietary $L A B$ in the present study. This was similar to the report that $L A B$ increased hemoglobin, albumin and total protein, but decreased cholesterol, total bilirubin, creatinine of broilers (Liu et al., 2018c; Wang et al., 2018). Others reported that $L$. acidophilus (strain D2/CSL CECT 4529) decreased egg lipid content of laying hens (Forte et al., 2016); L. plantarum (strain MDL1118) and E. faecium strain (MDF1104) removed yolk cholesterol by 58 and 38\%, respectively, when incubated in medium containing $4 \%$ egg yolk (Liu et al., 2013). However, commercial probiotics Bioplus and Primalac increased the concentration of total cholesterol in broilers (Kivi et al., 2015).

Some probiotic LAB strains have been reported promising treatments for high cholesterol and bile acid content (Singhal et al., 2019), but information about LAB effects on cholesterol metabolism is unavailable. The present study is the first to report the effect of dietary probiotics on the gut mucosal 
cholesterol content and its downstream metabolites in animals. The observed decreased concentration of cholesterol and bile acid in serum and jejunal mucosa reported here suggest that LAB may slow the rates of cholesterol synthesis or promote its catabolism during the enterohepatic circulation. Bile acids, the major endproduct of cholesterol metabolism, are synthesized in the liver and secreted via bile into the intestine to aid the absorption of fat-soluble vitamins and dietary fat (Di Ciaula et al., 2017).

Simultaneous measurements of biliary and intestinal cholesterol secretion in mice showed that plasma cholesteryl ester transfer protein (CETP) altered the route of cholesterol elimination from the body in mice fed a high fat, high cholesterol diet (Li et al., 2019). Overexpression of bile salt hydrolase by a Lactobacillus strain reduced cholesterol absorption and increased cholesterol catabolism in mice fed a high cholesterol diet (Wang et al., 2019c). In the present study, diets did not contain cholesterol, and only biosynthesis de novo provided cholesterol to the laying hens. Chickens have CETP, but typically consume low fat, lower (in case of diets containing animal derived components) or no cholesterol diets, and so whether the $L A B$ strains affect the route of cholesterol elimination by influencing CETP needs further study. Factors that influence cholesterol absorption, de novo synthesis and metabolism are subjects of extensive research in humans (Alphonse and Jones, 2016). Similar studies are not available for hens, and details of these same topics are still throughout egg production are poorly described.

Notably, in addition to processes related to changes in bile metabolism and excretion, Reis et al. (2017) suggested that incorporation, and assimilation of cholesterol into cell membranes or gametes are possible potential mechanisms responsible for the cholesterol lowering effect of probiotics. Outcomes reported here showed that $L A B$ treatments lowered cholesterol concentrations in yolk, serum and mucosa, coincident with reduced tissue HMGR expression, which indicates reduced cholesterol biosynthesis in these hens fed a cholesterol free diet. Thus, the inhibition of cholesterol biosynthesis in the liver or other tissues can be another potential mechanism by which probiotics could produce hypocholesterolaemic effects. Furthermore, it is known that hypocholesterolaemic effects vary among probiotics strains, as well as the physiological state and diet type of the animal ingesting them.

Cholesterol is also a precursor molecule in the biosynthesis of steroid hormones and vitamin
D. Pregnenolone is a cholesterol metabolite and precursor/metabolic intermediate in the biosynthesis of progestogens, androgens, estrogens, glucocorticoids, and mineralocorticoids (Weng \& Chung, 2016). Thus, there could be concern whether probiotic mediated cholesterol lowering has a negative effect on the critical hormone and vitamin D production by precursor limitation. While literature is unavailable on this point, results from the present study found that dietary $L A B$ did not affect tissue concentrations of pregnenolone, indicating that $L A B$ has no negative influences on the synthesis of steroid hormones. In addition, hens continued to lay eggs and in fact increased egg production. Cholesterol is a precursor for bile acids and there may be preferential use of cholesterol for critical precursor functions. Calcitriol, the active form of vitamin $D$, decreased in the serum of hens fed the low $L A B$ diet, but not in hens fed the medium and high $L A B$ dose diets. Likely, LAB have negligible negative effects on vitamin D metabolism and its related functions, however, confirmation studies are of interest.

Cholesterol biosynthesis de novo, is largely controlled by a crucial rate limiting enzyme HMGR. This enzyme is controlled by four distinct mechanisms: feed-back inhibition, control of gene expression, rate of enzyme degradation and phosphorylationdephosphorylation (DeBose-Boyd, 2008; Liu et al., 2009). The present study measured the mRNA expression of HMGR and related genes including PPP2CA, PPP2CB, PPP3CA, PRKAA1, PRKAA2, and STK11, and found that dietary $L A B$ dose above $3 \times$ $10^{7} \mathrm{cfu} / \mathrm{kg}$ significantly downregulated the expression of these genes in the liver. The findings indicate that cholesterol biosynthesis is reduced by high-dose $L A B$ and suggests that ingested $L A B$ may also act by regulating liver and gut gene expression.

In the liver, the effect of LAB on mRNA profiles was a general dose-dependent reduction in gene expression of varying levels of significance. However, in the jejunal mucosa, LAB did not influence STK11, PRKAA2, and PPP3CA, whereas only high dose of $L A B$ upregulated PPP2CA and PPP2CB. Expression of PPKAA1 and HMGR genes were reduced by $L A B$ in both the liver and mucosa, with mucosa less affected than liver. A study reported that STK11 downregulation decreased intracellular cholesterol levels in macrophages treated with the isoflavone puerarin (Li et al., 2017). AMPK subunits, PRKAA1 and PRKAA2, harbored largely nonoverlapping genetic determinants for body fat mass, glucose and cholesterol metabolism (Randrianarisoa et al., 2019), and were activated by aerobic exercise 
training in mice (Ferreira et al., 2017). There are no data in the nutrition on possible roles played by dietary factors in the activities of AMPK subunits. It is known that PPP2CA and PPP2CB, the coding genes of protein phosphatase catalytic subunits, can be inhibited by a cholesterol rich diet in mice (Pichavaram et al., 2019). Besides HMGR gene expression for cholesterol regulation, other mechanisms such as enzyme degradation rates as well as rates or regulators of phosphorylation-dephosphorylation need further study.

In summary, the three doses of $L A B$ decreased tissue cholesterol and bile acid concentrations. Diets containg $3 \times 10^{9} \mathrm{cfu} / \mathrm{kg}$ of the LAB mixture increased laying rate, egg mass, and yolk phospholipid concentrations, but decreased yolk concentrations of triglyceride and phosvitin. These changes accompanied increased expression of the PPP2CA and PPP2CB genes in jejunal mucosa, as well as reduced expression of all hepatic genes related to cholesterol synthesis and PRKAA1 and HMGR expression in the jejunal mucosa. Dosedependent decreases in cholesterol, phosvitin, serum bile acid concentrations and associated changes in hepatic gene expression in conjunction with improved egg performance suggest that $L A B$ can be an effective additive to decrease cholesterol in yolk. The probiotic mixture acts in part by regulating hepatic cholesterol synthesis at the point of HMGR.

\section{ACKNOWLEDGEMENTS}

N. L., Q. D., H. S. and J. W. conceived the project, and developed the overall research plan and had study oversight. Q. D. and Y. L. conducted the research and oversaw the analysis of the samples. N. L. and H. S. performed the statistical analysis. Prof. R. Walzem at Texas A\&M University reviewed the manuscript.

\section{CONFLICT OF INTEREST STATEMENT}

The authors have no conflicts of interest.

\section{REFERENCES}

Ahn DU, Lee JI, Jo C, Sell JL. Analysis of cholesterol oxides in egg yolk and turkey meat. Poultry Science 1999;78:1060-1064.

Alonso L, Fontecha J, Cuesta P. Combined effect of Lactobacillus acidophilus and $\beta$-cyclodextrin on serum cholesterol in pigs. British Journal of Nutrition 2016;115:1-5.

Alphonse PA, Jones PJ. Revisiting human cholesterol synthesis and absorption: the reciprocity paradigm and its key regulators. Lipids 2016;51:519-536.
Aminlari L, Shekarforoush SS, Hosseinzadeh S, Nazifi S, Sajedianfard J, Eskandari MH. Effect of probiotics Bacillus coagulans and Lactobacillus plantarum on lipid profile and feces bacteria of rats fed cholesterolenriched diet. Probiotics and Antimicrobial Proteins 2019;11:11631171.

Cha D, Park Y. Association between dietary cholesterol and their food sources and risk for hypercholesterolemia: The 2012-2016 Korea national health and nutrition examination survey. Nutrients 2019;11:846.

Culpepper T, Rowe CC, Rusch CT, Burns AM, Federico AP, Girard SA, et al. Three probiotic strains exert different effects on plasma bile acid profiles in healthy obese adults: randomised, double-blind placebocontrolled crossover study. Beneficial Microbes 2019;10:497-509.

DeBose-Boyd RA. Feedback regulation of cholesterol synthesis: sterolaccelerated ubiquitination and degradation of HMG COA reductase. Cell Research 2008;18:609-621.

Di Ciaula A, Garruti G, Lunardi Baccetto R, Molina-Molina E, Bonfrate L, Wang DQ, et al. Bile acid physiology. Annals of Hepatology 2018;16:414

Ding K, Jiang Q, Wang J, Liu N, Zhang F. Effect of tetramethylpyrazine on growth performance, Campylobacter jejuni carriage and endogenous antimicrobial peptides in rabbits. Czech Journal of Animal Science 2019a;64:465-471

Ding K, Wang J, Liu N, Zhang F. Effect of Artemisia apiacea Hance on growth performance, cecal opportunistic bacteria, and microbicidal peptides in rabbits. Revista Brasileira de Zootecnia 2019b;48:e20190118.

Ferreira GS, Pinto PR, Iborra RT, Del Bianco V, Santana MF, Nakandakare $E R$, et al. Aerobic exercise training selectively changes oxysterol levels and metabolism reducing cholesterol accumulation in the aorta of Dyslipidemic mice. Frontiers in Physiology 2017;8:644.

Forte C, Moscati L, Acuti G, Mugnai C, Franciosini MP, Costarelli S, et al. Effects of dietary Lactobacillus acidophilus and Bacillus subtilis on laying performance, egg quality, blood biochemistry and immune response of organic laying hens. Journal of Animal Physiology and Animal Nutriton 2016;100:977-987

Howles PN. Cholesterol absorption and metabolism. Methods in Molecular Biology 2016;1438:177-197

Kivi RK, Dadashbeiki M, Seidavi A. Growth, body characteristics and blood parameters of ostrich chickens receiving commercial probiotics. Spanish Journal of Agricultural Research 2015;13:604.

Li CH, Gong D, Chen LY, Zhang M, Xia XD, Cheng HP, et al. Puerarin promotes ABCA1-mediated cholesterol efflux and decreases cellular lipid accumulation in THP-1 macrophages. European Journal of Pharmacology 2017;811:74-86.

Li J, Pijut SS, Wang Y, Ji A, Kaur R, Temel RE, et al. Simultaneous determination of biliary and intestinal cholesterol secretion reveals that CETP (cholesteryl ester transfer protein) alters elimination route in mice. Arteriosclerosis, Thrombosis, and Vascular Biology 2019;39:19861995.

Liu GF, Fang WN, Lin HC, Wang XF, Fu JL, Wang AG. Expression of HMGR and corresponding cholesterol content in tissues of two pig breeds. Animal 2009;3:1436-1441

Liu H, Yang C, Jing Y, Li Z, Zhong W, Li G. Ability of lactic acid bacteria isolated from mink to remove cholesterol: in vitro and in vivo studies. Canadian Journal of Microbiology 2013;59:563-569.

Liu N, Deng X, Liang C, Cai H. Effect of broccoli residues fermented with probiotics on the growth performance and health status of broilers challenged with Clostridium perfringens. Brazilian Journal of Poultry Science 2018a;20:625-632. 
Liu N, Ding K, Wang J, Deng Q, Gu K, Wang J. Effects of lactic acid bacteria and smectite after aflatoxin B1 challenge on the growth performance, nutrient digestibility and blood parameters of broilers. Journal of Animal Physiology and Animal Nutrition 2018c;102:953-961.

Liu N, Ru Y, Wang J, Xu T. Effect of dietary sodium phytate and microbial phytase on the lipase activity and lipid metabolism of broiler chickens. British Journal of Nutrition 2010;103:862-868.

Liu N, Wang JQ, Liu ZY, Wang YC, Wang JP. Comparison of probiotics and clay detoxifier on the growth performance and enterotoxic markers of broilers fed diets contaminated with aflatoxin B1. Journal of Applied Poultry Research 2018b;27:341-348.

Mikulski D, Jankowski J, Naczmanski J, Mikulska M, Demey V. Effects of dietary probiotic (Pediococcus acidilactici) supplementation on performance, nutrient digestibility, egg traits, egg yolk cholesterol, and fatty acid profile in laying hens. Poultry Science 2012;91:2691-2700.

Pichavaram P, Mani AM, Singh NK, Rao GN. Cholesterol crystals promote endothelial cell and monocyte interactions via H2O2-mediated PP2A inhibition, NFKB activation and ICAM1 and VCAM1 expression. Redox Biology 2019;24:101180.

Randrianarisoa E, Lehn-Stefan A, Krier J, Böhm A, Heni M, Hrabě De Angelis $\mathrm{M}$, et al. AMPK subunits harbor largely nonoverlapping genetic determinants for body fat mass, glucose metabolism, and cholesterol metabolism. The Journal of Clinical Endocrinology and Metabolism 2019;105:dgz020.

Reis SA, Conceição LL, Rosa DD, Siqueira NP, Peluzio MC. Mechanisms responsible for the hypocholesterolaemic effect of regular consumption of probiotics. Nutrition Research Reviews 2017;30:36-49.

Roager HM, Sulek K, Skov K, Frandsen HL, Smedsgaard J, Wilcks A, et al. Lactobacillus acidophilus NCFM affects vitamin E acetate metabolism and intestinal bile acid signature in monocolonized mice. Gut Microbes 2014;5:296-303.

Saez-Lara MJ, Gomez-Llorente C, Plaza-Diaz J, Gil A. The role of probiotic lactic acid bacteria and Bifidobacteria in the prevention and treatment of inflammatory bowel disease and other related diseases: a systematic review of randomized human clinical trials. BioMed Research International 2015;2015:505878.
Schmittgen TD, Livak KJ. Analyzing real-time PCR data by the comparative CT method. Nature Protocols 2008;3:1101-1108.

Singhal N, Maurya AK, Mohanty S, Kumar M, Virdi JS. Evaluation of bile salt hydrolases, cholesterol-lowering capabilities, and probiotic potential of Enterococcus faecium isolated from rhizosphere. Frontiers in Microbiology 2020;10:1567.

Wang G, Huang W, Xia Y, Xiong Z, Ai L. Cholesterol-lowering potentials of Lactobacillus strain overexpression of bile salt hydrolase on high cholesterol diet-induced hypercholesterolemic mice. Food \& function. 2019c;10:1684-1695.

Wang J, Lin L, Jiang Q, Huang W, Liu N. Effect of supplemental lactic acid bacteria on the growth performance, glutathione turnover and aflatoxin B1 removal in lambs. Czech Journal of Animal Science 2019a;64:272-278

Wang J, Lin L, Jiang Q, Huang W, Liu N. Probiotics and clay detoxifier protected growth performance and intestinal barrier of lambs fed diets contaminated with aflatoxin B1. Indian Journal of Animal Sciences 2019b;89:658-662.

Wang $Y$, Dong $Z$, Song $D$, Zhou $H$, Wang $W$, Miao $H$, et al. Effects of microencapsulated probiotics and prebiotics on growth performance, antioxidative abilities, immune functions, and caecal microflora in broiler chickens. Food and Agricultural Immunology 2018;29:859-869.

Weng $\mathrm{JH}$, Chung BC. Nongenomic actions of neurosteroid pregnenolone and its metabolites. Steroids 2016;111:54-59.

Zhai Q, Liu Y, Wang C, Qu D, Zhao J, Zhang H, et al. Lactobacillus plantarum CCFM8661 modulates bile acid enterohepatic circulation and increases lead excretion in mice. Food and Function 2019;10:1455-1464.

Zhao $\mathrm{H}$, Zhang $\mathrm{F}$, Chai J, Wang J. Effect of lactic acid bacteria on listeria monocytogenes infection and innate immunity in rabbits. Czech Journal of Animal Science 2020;65:23-30. 